\title{
SISTEMAS DE CESIÓN CONTROLADA POR VÍA INTRAOCULAR
}

\author{
INTRAOCULAR DRUG DELIVERY SYSTEMS
}

\author{
RINCÓN ALARCÓN A ${ }^{1}$, MOLINA MARTÍNEZ IT ${ }^{1}$
}

Las patologías que afectan al segmento posterior del ojo se caracterizan por ser devastadoras y comprometer la visión en un gran número de sujetos. Por tanto, resulta primordial tanto la instauración rápida del tratamiento como el mantenimiento de concentraciones eficaces en el lugar de acción durante el mayor tiempo posible. Sin embargo, la eficacia terapéutica de los tratamientos farmacológicos en esta zona se encuentra limitada, fundamentalmente, por la dificultad de acceso de la sustancia activa a los tejidos diana.

En la actualidad, se acude a distintas formulaciones de efecto local y sistémico, encaminadas a conseguir concentraciones eficaces en el interior del ojo.

Si se recurre a la vía tópica, las resistencias que ofrecen la córnea, el cristalino y las barreras hematoacuosa y hematorretiniana hacen que, en un gran número de ocasiones, los niveles de fármaco resulten ineficaces en vítreo, retina y coroides. Por otra parte, si se acude a la vía oral el acceso del fármaco al segmento posterior desde circulación general es muy bajo. Estos hechos hacen que se deba acudir a un depósito directo de la sustancia activa en el lugar de acción o en zonas colindantes con el propósito de instaurar el efecto, de forma rápida y eficaz. Las inyecciones perioculares e intraoculares resultan más efectivas aunque, en ningún caso, se encuentran libres de generar efectos adversos. Cuando se acude a las inyecciones intravítreas el tratamiento requiere, generalmente, administraciones sucesivas cuya frecuencia depende de la semivida intravítrea del fármaco. A pesar de las ventajas que aporta esta administración, no se encuentra exenta de riesgos ya que la frecuencia de las inyecciones va asociada con efectos secundarios impor- tantes como cataratas, desprendimiento de retina, hemorragias vítreas y endoftalmitis.

El tratamiento ideal para las patologías que afectan al segmento posterior apuntaría hacia una formulación con la que se consiguiera, en una aplicación única, la liberación inicial de una cantidad del fármaco igual a la dosis de choque, seguida de una liberación lenta y gradual de la sustancia activa durante un período de tiempo determinado. Con este fin se emplean en la actualidad los sistemas de acción prolongada como los preparados «depot». En estas formulaciones, la sustancia activa presenta una lenta velocidad de disolución y es ésta la responsable de la duración del efecto. Un ejemplo clásico de este tipo de formulaciones lo constituyen las inyecciones de triamcinolona.

Si se acude a sistemas de cesión controlada la ventaja fundamental que aportan es la capacidad de liberación de la sustancia activa durante un período prolongado de tiempo. Dentro de los sistemas intraoculares de liberación controlada que se han desarrollado hasta el momento, caben destacar los implantes intraoculares, los dispositivos esclerales, los liposomas y las micro y nanopartículas. Los sistemas, anteriormente mencionados, pueden ser biodegradables o no en función del polímero utilizado. En cualquier caso, el biomaterial empleado para su elaboración debe ser biocompatible y tolerable.

Dentro de los dispositivos intravítreos aprobados por la FDA para su uso humano se encuentran dos implantes no biodegradables denominados Vitrasert, y Retisert ${ }^{\mathrm{TM}}$. El primero es de ganciclovir, y ha sido empleado para el tratamiento de la retinitis por citomegalovirus y el segundo de acetónido de fluocinolona para el tratamiento de la uveítis del seg-

\footnotetext{
1 Dpto. de Farmacia y Tecnología Farmacéutica. Facultad de Farmacia. UCM. España.

E-mail: iremm@farm.ucm.es
} 
mento posterior. Ambos implantes son no biodegradables por lo que es necesaria su retirada al final del tratamiento (1).

Dentro de los sistemas de liberación controlada de fármacos en el vítreo, utilizando la esclera se han desarrollado hasta el momento implantes esclerales, clavos esclerales, sistemas de gelificación in situ (Pluronic F-127) y sistemas bioadhesivos. Los implantes esclerales han sido diseñados como dispositivos menos invasivos que las inyecciones intraoculares, utilizándose para su fabricación tanto polímeros no biodegradables [acetato de etilvinilo (EVA)] como biodegradables [poli- $D L$-láctico (PLA)]. Con ambos tipos de implantes se han obtenido niveles terapéuticos de la sustancia activa en el vítreo, retina y coroides, por lo que han sido propuestos como posibles sistemas eficaces de administración de fármacos. Si los sistemas son biodegradables aportan la ventaja de desaparecer del lugar de acción una vez ejercido el efecto. Este hecho resulta sumamente provechoso, ya que no se requiere la retirada final del mismo.

Los sistemas «particulares» están constituidos por los liposomas y las micro y nanopartículas. Las principales ventajas estriban en su administración mediante inyección y su gradual desaparición, ya que se preparan a partir de polímeros biodegradables (2-5).

La administración de liposomas por vía intraocular ha sido objeto de diversos estudios. Así, se ha logrado inhibir la retinitis por citomegalovirus en conejos, mediante la inyección intravítrea de liposomas que contenían un profármaco lipídico de ganciclovir. Igualmente, se han empleado liposomas para la administración intravítrea de oligonucleótidos en el tratamiento de infecciones virales oculares como la del herpes simple o del citomegalovirus, encontrándose que estas vesículas lipídicas eran capaces de proteger a los oligonucleótidos de su degradación por las nucleasas. Sin embargo, la administración intravítrea de liposomas conlleva desventajas, como la aparición de cuerpos vítreos que se localizan, generalmente, en la parte inferior del ojo, con la consecuente disminución de la agudeza visual. Estos artefactos tienden a desaparecer entre los 14 y 21 días después de la administración. Aunque los liposomas resulten sumamente ventajosos presentan otros inconvenientes que limitan su utilización terapéutica como son su reducido período de conservación y su baja estabilidad en fluidos biológicos que puede ocasionar la liberación prematura del principio activo.
Las suspensiones coloidales de micro y nanopartículas poliméricas, constituyen los sistemas que en la actualidad representan un mayor grado de innovación y versatilidad. Las diferencias entre estas partículas radican en el tamaño y así se consideran micropartículas las de un tamaño superior a $1 \mu \mathrm{m}$, mientras que las nanopartículas serán las que poseen tamaños inferiores a éste. Los polímeros más empleados para la fabricación de micro y nanopartículas de administración intraocular, son los derivados del ácido láctico-glicólico. Estos polímeros están aceptados por la Food and Drug Administration (FDA), para su utilización en humanos y son empleados, desde hace años, como materiales de sutura. Las micropartículas, específicamente las microesferas, han sido desarrolladas en la terapéutica oftalmológica para el tratamiento de distintas patologías. Por ejemplo: se han desarrollado microesferas de adriamicina, 5-fluoracilo (5-FU) y ácido retinoico para el tratamiento de la vitreorretinopatía proliferativa; de dexametasona para la prevención de posibles uveítis después de procedimientos quirúrgicos; de aciclovir para el tratamiento de la necrosis retiniana y de ganciclovir para la retinitis por citomegalovirus. La administración intraocular de micropartículas se lleva a cabo mediante la inyección de una suspensión de las mismas, a través de una aguja cuyo diámetro se selecciona en función del tamaño de las partículas. Las más utilizadas han sido las de grosor entre 25-30 G para tamaños comprendidos entre 1 y 50 micrómetros y las de $18 \mathrm{G}$ para partículas de hasta 500 micrómetros.

La esterilidad es un factor crítico para los sistemas de administración intraocular, prefiriéndose un proceso de esterilización final del producto, a la fabricación en condiciones asépticas. Sin embargo, alguno de polímeros empleados como los derivados del ácido láctico y glicólico son susceptibles a la mayoría de los métodos de esterilización habitualmente empleados (calor y óxido de etileno). Hace algunos años aparecieron los primeros trabajos referentes a la utilización del método basado en la radiación ionizante con rayos gamma, para la esterilización de microesferas destinadas a uso parenteral. Los rayos gamma tienen una alta capacidad de penetración y la dosis necesaria para lograr la esterilización se encuentra comprendida entre 25 y 40 kGy. Una gran cantidad de materiales son compatibles con la esterilización por radiaciones gamma, por lo que es ampliamente aceptado como método de esterilización para materiales poliméricos, den- 
tro de los que se incluyen polietileno, poliésteres, poliestirenos, polisulfóxidos y policarbonatos. Este tipo de esterilización es el método utilizado habitualmente para productos sanitarios termolábiles y el más idóneo para este tipo de formulaciones, principalmente, por su alto poder de penetración, baja reactividad química, bajos niveles de residuos, pequeños cambios de temperaturas en la muestra y las pocas variables a controlar durante el proceso. Sin embargo, la dosis que garantiza la esterilidad de un producto farmacéutico $(25 \mathrm{kGy}$, dosis de sobreesterilización descrita por las farmacopeas Española y Americana) genera una disminución significativa en el peso molecular del polímero y, por tanto, afecta considerablemente a las propiedades del producto final. Este problema parece haber sido solventado mediante la utilización de bajas temperaturas durante el tiempo de exposición de las micropartículas a la radiación. A todo esto hay que añadir las propiedades físico-químicas de la sustancia activa que pueden ser alteradas también, tras ser expuestas a la radiación.

A pesar de los avances logrados en este campo, ninguno de los sistemas anteriormente mencionados funciona a plena satisfacción y la dosificación intraocular de medicamentos está demandando el desarrollo de formulaciones y de nuevos materiales de propiedades más avanzadas que sus predecesores. Como exigencia imprescindible el material utilizado como modulador de la cesión y sus productos de degradación deben ser altamente biocompatibles y exentos de toxicidad. Además deben poseer unas características que le permitan la incorporación de sustancias activas de distinta naturaleza siendo a la vez capaces de liberarlas de forma controlada en el segmento posterior del ojo.

\section{BIBLIOGRAFÍA}

1. Yasukawa T, Ogura Y, Tabata Y, Kimura H, Wiedemann $P$, Honda Y. Drug delivery systems for vitreoretinal diseases. Progr Retin Eye Res 2004; 23: 253-281.

2. Bochot A, Couvreur P, Fattal E. Intravitreal administration of antisense oligonucleoutides: Potential of liposomal delivery. Prog Retin Eye Res 2000; 19: 131-147.

3. Velez G, Whitcup SM. New developments in sustained release drug delivery for the treatment of intraocular disease. Br J Ophthalmol 1999; 83: 1225-1229.

4. Herrero-Vanrell R, Refojo MF. Biodegradable microspheres for vitreoretinal drug delivery. Adv Drug Deliv Rev 2001; 52: 5-16.

5. Martínez-Sancho C, Herrero-Vanrell R, Negro S. Study of gamma-irradiation effects on aciclovir poly (D,L-lacticco-glycolic) acid microspheres for intravitreal administration. J Control Release 2004; 99: 41-52. 